\title{
Spatial dynamics of late successional species under Pinus nigra stands in the northern Apennines (Italy)
}

\author{
Giustino TONON ${ }^{\mathrm{a} *}$, Pietro PANZACCHI ${ }^{\mathrm{a}}$, Giacomo GRASSI ${ }^{\mathrm{a}}$, Minotta GIANFRANCO ${ }^{\mathrm{b}}$, Lucia CANTONI $^{\mathrm{a}}$, \\ Umberto BAGNARESI ${ }^{\mathrm{a} \dagger}$ \\ ${ }^{a}$ Dipartimento di Colture Arboree, Università di Bologna Via Fanin 46, 40127 Bologna, Italy \\ b Dipartimento AGROSELVITER, Università di Torino, Via Leonardo da Vinci 44, 10095 Grugliasco (TO), Italy
}

(Received 18 October 2004; accepted 8 April 2005)

\begin{abstract}
The present study was carried out in three plots $(20 \times 50 \mathrm{~m})$ established in even-aged Pinus nigra (Austrian black pine) stands located at approximately the same altitude, characterised by a similar age but showing different growth rate. Spatial distribution of natural regeneration (NR) were examined for each species by calculating Ripley's $K$ and Moran index and by analysing their age- and size structure. Although the species mixture of NR differed among the plots, Abies alba was always the most frequent. Results showed that the clumped distribution of NR prevails over the random one. The spatial autocorrelation analysis indicated at least two modes of space colonisation in line with clumped distribution of NR. In the first, the seedlings occupy different micro-areas in different times, whereas in the second the colonisation process occurs in the same micro-area for a more extended time. The resulting structure of NR is constituted by several small patches of different age in the first case or by patches with a similar uneven-aged structure in the second. These different colonisation patterns could be ascribed respectively to short-term disturbances such as sudden opening in the canopy and litter removal in the first case and to longterm disturbances or the presence of scarcely modifiable environmental factors such as soil characteristics and micro-morphology in the second. However, the colonisation process was always temporally limited. Age structures of the different species overlapped and were not related to stand basal area. As both colonisation patterns are likely to increase the structural and floristic complexity of the future stands, our data further confirm the important role played by Pinus nigra in recovering degraded lands.
\end{abstract}

natural regeneration / Pinus nigra / Ripley's K / Moran's I / spatial pattern

Résumé - Dynamique spatiale de la régénération forestière sous des pins noirs dans le nord des Apennins (Italie). Cette étude a été menée dans 3 placeaux $(20 \times 50 \mathrm{~m})$ installés dans des peuplements équiennes de Pins noirs situés approximativement à la même altitude, caractérisés par un âge similaire mais présentant des taux de croissance différents. La distribution spatiale de la régénération naturelle (NR) a été étudiée pour chaque espèce en calculant les index de Ripley et de Moran et en analysant leur âge et la taille des structures. Bien que le mélange des espèces de la régénération naturelle diffère selon les placeaux, Abies alba était toujours le plus fréquent. Les résultats montrent que la distribution groupée de NR prévaut sur une distribution au hasard. L'analyse d'autocorrélation spatiale indique au moins deux modes de colonisation de l'espace allant dans le sens d'une distribution groupée de la RN. D'abord, les semis occupent à différents moments différentes microsurfaces tandis que dans un deuxième temps les processus de colonisation arrivent dans la même microsurface pour une durée plus importante. La structure résultante de la NR est constituée par plusieurs petites taches d'âge différent dans le premier cas ou de taches avec des structures similaires d'âge différent dans le second. Ces différents modèles de colonisation pourraient être attribués respectivement à des perturbations à court terme tels que une ouverture brutale dans la canopée et un enlèvement de la litière dans le premier cas, et des perturbations à long terme ou la présence de quelques facteurs environnementaux modifiables telles que les caractéristiques du sol et la micromorphologie dans le second. Cependant les processus de colonisation étaient toujours temporairement limités. Les structures des âges des différentes espèces se recoupaient et n'étaient pas reliées à la surface terrière du peuplement. Alors que les deux modèles de colonisation sont probables dans l'accroissement de la complexité structurale et floristique des futurs peuplements, nos données confirment davantage le rôle important joué par le pin noir en colonisant des terrains dégradés.

régénération naturelle / Pinus nigra / Ripley's K / Moran's I / modèle spatial

\section{INTRODUCTION}

The description of the spatial pattern of natural regeneration (NR) in forest ecosystems is a key-step to understand their dynamic and to model the NR process [15]. The spatial pattern of trees in forest stands reflects the complex interactions among the forest management, the microenvironments, the climate factors, the inter- and intra-specific plant competition and the

\footnotetext{
* Corresponding author: gtonon@agrsci.unibo.it
} 
occurrence of natural disturbances [34]. The description and the interpretation of this spatial information are becoming a major challenge in the fields of forestry, ecology and forest management [5, 13, 34]. Several methods, called point pattern analysis, have been developed in order to describe the spatial point pattern of a population of mapped plants [16]. Generally, the main objective of these tools of spatial statistics is to determine whether the plants have a random, regular or aggregated spatial distribution, in order to infer the nature of the process that may have originated the observed structure $[11,14,16]$. A more sophisticate approach is to detect particular spatial pattern at different scales. Although several indexes have been proposed with this aim [14], we choose the second-order analysis based on Ripley's $K$-function [42], which has been widely applied to analyze plant distribution at different scales in forest ecosystems ranging from tropical to boreal forests $[2,11,30$, 42]. Moreover a bivariate extensions $\left(K_{12}\right)$ of Ripley's $K$-function proposed by Lotwick and Silverman [32] permits to verify the spatial interaction between two types of plant populations (i.e. two species, adult and young individuals, etc.).

A further analysis to characterize the spatial structure, commonly called surface spatial analysis, is the spatial autocorrelation. This analysis can be applied to several characteristics such as size and age of mapped trees. Autocorrelation can be estimated using specific spatial autocorrelation indexes such as Moran's $I$ [35] and Geary's c [25]. Spatial autocorrelation indicates how much the value of a parameter with known spatial coordinates affects the value of the same parameter in the neighbourhood.

In the present paper we use the term spatial pattern in a broad sense considering both spatial distribution and spatial association. In order to have a satisfactory description of the spatial patterns of NR we used a combination of point pattern and surface spatial analysis.

As observed by several authors $[5,19,34]$ we believe that the analysis of spatial patterns within and between groups of trees differing in species, size, competition capacity and ecological requirements can help to generate hypotheses on the causal factors that have produced the observed patterns and consequently to formulate appropriate management options. At present, no data are available on this issue for late successional forest species under artificial Pinus nigra ssp. nigra (Austrian black pine) plantations, despite of the large diffusion and importance of these stands in many regions of southern Europe. During the first half of 20th century about 100000 ha in the Apennines area (Italy) were planted with this tree species in order to recover abandoned and overgrazed lands $[8,9,21]$. The social-economical changes occurred in the Apennines area during the last fifty years caused a progressive reduction in the silvicultural practices in these plantations. As a consequence, many stands of Pinus nigra are now very dense and highly susceptible to abiotic factors (mainly wind and snow). Given the current attention toward sustainable forestry, their management is now addressed to favour NR, with the aim to obtain ecological systems with increased resistance to external factors $[1$, 51]. The long-term objective is to restore the structure, the species diversity and the function of a native forest ecosystem through the gradual conversion of these coniferous monocultures into natural broad-leaved or mixed native coniferous forests [51].
Table I. Main characteristics of the studied plots $(20 \times 50 \mathrm{~m})$.

\begin{tabular}{lccc}
\hline & Plot 1 & Plot 2 & Plot 3 \\
\hline Altitude (m a.s.1.) & 1050 & 1110 & 1160 \\
Orientation & S-SW & - & NW \\
Average slope (\%) & 30 & 2 & 22 \\
Age of the mature pine trees & 76 & 74 & 74 \\
(years) & & & \\
Mature pine trees density & 870 & 990 & 1380 \\
(Stems ha ${ }^{-1}$ ) & & & \\
Volume (m ${ }^{3}$ ha $\left.^{-1}\right)$ & 777.7 & 263.4 & 551.4 \\
Basal area (m ha $\left.^{-1}\right)$ & 101.5 & 40.8 & 80.6 \\
$\mathrm{D}_{\mathrm{g}}(\mathrm{cm})$ & 38.8 & 22.9 & 27.3 \\
$\mathrm{H}_{\mathrm{g}}(\mathrm{m})$ & 25.5 & 9.2 & 16.2 \\
$\mathrm{H}_{\text {Dom }}(\mathrm{m})$ & 27.5 & 16.8 & 20.8 \\
\hline
\end{tabular}

$\mathrm{D}_{\mathrm{g}}$ : diameter of the average tree, $\mathrm{H}_{\mathrm{g}}$ : average height, $\mathrm{H}_{\text {dom }}$ : dominant height.

In this context, the understanding of the ecological mechanisms driving the establishment and the dynamics of NR is an essential goal from both an ecological and a silvicultural point of view [55].

At present, the literature on the vegetation dynamics within man-made Pinus nigra stands is scarce $[10,51]$ and focused on post-fire environmental conditions [22, 36, 37].

In this study we report the results of the spatial analysis of late-successional species regeneration in three plots of artificial Pinus nigra stands in the northern Apennines. For each species forming NR we describe both point and surface patterns with the aim to characterise the spatial pattern of NR at different scales, and to highlight the possible relationships among the species forming NR and between mature trees of Pinus nigra and NR. Furthermore, we studied temporal dynamic of NR by analysing its age-structure in relation to surface pattern and biometric parameters. The resulting spatial and temporal information were then used to generate hypotheses on the nature of casual factors that have produced the observed pattern.

\section{MATERIALS AND METHODS}

\subsection{Study area}

The study was carried out in the northern Apennines (Mt. Tresca area, $44^{\circ} 08^{\prime} \mathrm{N}, 10^{\circ} 55^{\prime}$ E) during 2002 . Three rectangular plots $(20 \times 50 \mathrm{~m})$ were established in three Pinus nigra stands planted at the beginning of 20th century on former grazed lands and located about at the same elevation. The average annual rainfall for the area is 1952 $\mathrm{mm}$ with two peaks at November and May; the average annual temperature is $12{ }^{\circ} \mathrm{C}$ and the mean January and July temperatures are 0.5 and $19.1{ }^{\circ} \mathrm{C}$, respectively. The elevation of the three plots ranged between 1050 and $1160 \mathrm{~m}$ a.s.l., the slope between 2 and 30\% (Tab. I). The plots were chosen with the aim to represent stands with similar age, growing in the same macroclimate area, but experiencing different site conditions as confirmed by different stand growth (Tab. I). Only stand of the plot 1 was subjected to a selective thinning in 1986. The area is characterised by several pure artificial stands of exogenous 
and native conifers such as Douglas fir (Pseudotsuga menziesii), Norway spruce (Picea abies) and silver fir (Abies alba). Even-aged beech (Fagus sylvatica) stands are also spreading throughout the area, while the presence of chestnut (Castanea sativa) and other broadleaves (Fraxinus spp., Alnus spp. Ostrya carpinifolia, etc.) is sporadic.

\subsection{Field procedures and tree mapping}

All saplings taller than $0.15 \mathrm{~m}$ and all Pinus nigra trees were mapped by a Cartesian co-ordinates system using electronic distance measuring instruments. Trees with stems rooted off the plot but with crowns intersecting plot boundaries were included to alleviate bias introduced by edge effects.

Diameters at breast height (dbh) of all individuals of Pinus nigra were recorded. Approximately $15 \%$ of canopy trees were subsampled for measurement of total height and crown width. The subsample was used to fit allometric equations for predicting crown width and tree height. Height was predicted as a log-linear function of dbh and crown width as a log-linear function of dbh and height. Data were used to calculate the standing volume using the species-specific volume table proposed by Meoni [33] for this area. The age of stands were assessed by historical documents and tree-rings counting of at least five woody cores per plot extracted by mean of a Pressler probe at $30 \mathrm{~cm}$ above ground. The main characteristics of the plots are summarised in Table I.

Species names, total height and diameter at ground level of all mapped saplings were recorded. The age of saplings was assessed by counting the inter-nodes for the conifers. In some case there was not a clear differentiation of nodes and some saplings were cut at ground level in order to estimate the age by rings counting. The age of chestnut saplings was estimated by counting the rings on woody cores extracted with the Pressler probe at ground level. Unfortunately it was not possible to evaluate the age of Fagus sylvatica saplings due to the hardness of the wood - and that of Ostrya carpinifolia due to the small dimensions of the stems.

\subsection{Univariate point pattern analysis of natural regeneration}

The purpose of point pattern analysis is to establish if NR is randomly distributed or not and to describe the type of spatial pattern. With this aim we used Ripley's $K(d)$ function, which is based on the variance (second order analysis) of all point-to-point distances in a two dimensional space $[42,44]$. This kind of analysis can identify different scales of spatial pattern and the distance where clustering or heterogeneity are significant [17]. The distance matrix $\delta_{i j}$ between all pairs of the saplings on the plots was tabulated and Ripley's $K$ calculated as follows:

$$
K(d)=A \sum_{i=1}^{n} \sum_{j=1}^{n} \frac{\delta_{i j}(d)}{n^{2}} \text { for } i \neq j
$$

where

$$
\delta_{i j}(d)=\begin{array}{ll}
1 & d_{i j} \leq d \\
0 & d_{i j}>d
\end{array}
$$

where $A$ is the area of the plot, $\mathrm{d}$ the distance interval and $n$ the number of trees in the plot [34]. We used a square root transformation $L(d)$ :

$$
L(d)=\sqrt{\frac{K(d)}{n}}-d
$$

that linearizes $K(d)$, stabilises its variance and has an expected value approximating zero under a random Poisson distribution [26, 34, 43]. Edge effects were corrected with a toroidal method [4, 26]. Monte Carlo method was used to simulate randomly generated plots of the same dimensions as the empirical plot. We done 19 simulations to compare the value of the function $K(d)$ with that expected from a randomly distribution of points. The spatial pattern can be described as clumped, random or regular at any distance $d$ if the calculated $K(d)$ function is greater, equal or lower than the $95 \%$ confidence envelopes, respectively.

\subsection{Bivariate point pattern analysis of natural regeneration}

In order to get information on the spatial relationships among the species forming NR and between NR and Pinus nigra populations we calculated the Ripley's $K_{12}$ function [16].

The Ripley's $K_{12}$ function is obtained as follows:

$$
K_{12}(d)=\frac{n_{2} \hat{K}_{12}(d)+n_{1} \hat{K}_{21}(d)}{n_{1}+n_{2}}
$$

where

$$
\begin{aligned}
& \hat{K}_{12}(d)=\frac{A}{n_{1} n_{2}} \sum_{i=1}^{n_{1}} \sum_{j=1}^{n_{2}} \delta_{i j}(d) \\
& \hat{K}_{21}(d)=\frac{A}{n_{1} n_{2}} \sum_{i=1}^{n_{1}} \sum_{j=1}^{n_{2}} \delta_{j i}(d)
\end{aligned}
$$

and $n_{1}$ and $n_{2}$ are the number of trees of two populations.

Values of $L_{12}(d)$ greater, equal or lower than the $95 \%$ confidence envelopes indicate positive association (attraction), spatial independence, and negative association (repulsion) between the two populations analysed, respectively.

\subsection{Spatial and temporal dynamics of natural regeneration}

The spatial-temporal dynamic of NR was studied in each plot by analysing age-structure of NR for each species and by calculating the spatial autocorrelation Moran's Index for the age, height and diameter of saplings. For the estimation of Moran's $I$, each variable $(z)$ was attached to the co-ordinates of tree $(x, y)$ and the index was calculated as follows:

$$
I(d)=\frac{\frac{\sum \sum w_{i j}(d)\left(x_{i}-\bar{x}\right)\left(x_{j}-\bar{x}\right)}{W(d)}}{\frac{\sum\left(x_{i}-\bar{x}\right)^{2}}{n}}
$$

where $d$ is the distance class, $w_{i j}(d)$ are elements of a weight matrix for which a value of 1 indicates that a pair of two samples, $x_{i}$ and $x_{j}$, are in the same distance class and a value of 0 indicates all other cases. $W(d)$ is the sum of all $w_{i j}(d)$ [19]. The index indicates how much the value of a parameter with known spatial coordinates is correlated to the values of the same parameter in the neighbour. Moran's $I$ ranges from -1 (negative autocorrelation) to 1 (positive autocorrelation) with an expected value close to zero in absence of spatial autocorrelation. The software RookCase v 0.9 [46] was used to calculate the Moran's Index. A graph showing how autocorrelation changes as a function of distance is an all-directional spatial correlogram. Each correlogram was tested for global significance at the 5\% level using Bonferoni procedures to correct for the dependence among the aurocorrelation coefficients calculated for each distance lag [31]. For significant correlograms we interpreted the shape of the curve only for the distances classes with at least 10 pairs of points. 
Table II. Species composition (\%) and plant density $\left(\right.$ stems ha $\left.{ }^{-1}\right)$ of natural regeneration in the studied plots.

\begin{tabular}{|c|c|c|c|}
\hline & Plot 1 & Plot 2 & Plot 3 \\
\hline Plant density $\left(\right.$ stem ha $\left.{ }^{-1}\right)$ & 1010 & 3800 & 1290 \\
\hline \multicolumn{4}{|l|}{ Species (\%) } \\
\hline Abies alba & 55.2 & 79.9 & 84.5 \\
\hline Castanea sativa & 21.0 & & \\
\hline Fagus sylvatica & 21.9 & & 10.8 \\
\hline Picea abies & & 5.6 & 1.6 \\
\hline Ostrya carpinifolia & & 11.6 & \\
\hline Others & 1.9 & 2.9 & 3.1 \\
\hline
\end{tabular}

\section{RESULTS}

\subsection{Species composition and size distribution of natural regeneration}

Although the species mixture of NR differed among the plots, Abies alba was the most frequent in each one. The plant density of NR in the examined plots was significantly different (Tab. II). On the whole, an inverse relationship between plant density of NR and stand basal area of adult population was discernible (Tabs. I and II). The analysis of the size-structure highlighted an higher asymmetry in the diameter and height distribution in plot 1 and 2 than in plot 3 (Fig. 1). Similarly, the amplitude of size distribution was higher in plot 1 and 2 than in plot 3 (Fig. 1).

Only for Abies alba it was possible to compare the three plots for bio-metric and chronological data and for their correlation. No significant difference was detectable between plot 2 and plot 3 for any possible relationship, while the correlation between age and height indicated that the height growth rate of Abies alba saplings was much higher in plot 2 than in the other plots (Fig. 2).

The saplings of Castanea sativa were present only in plot 1 . They showed the fastest growth rate in diameter with respect to the other species, but no significant correlation was detectable between age and height of saplings for this species (Fig. 2).

Both Abies alba and Picea abies were present in plot 2 wherein showed a similar relationships between diameter and height as well as a similar height and diameter growth rate as a function of the age (Fig. 2).

\subsection{Univariate point pattern analysis of natural regeneration}

Figure 3 shows the values of $L(d)$ as a function of the distance calculated for all NR and for each species separately. All the individuals of NR and those of Abies alba showed a significant clumped distribution for distances greater than $3 \mathrm{~m}$ in the plot 1 (Fig. 3). In the same plot the saplings of Fagus sylvatica resulted randomly distributed for distances smaller than $4 \mathrm{~m}$ and aggregated at all the other distances. On the contrary, Castanea sativa resulted randomly distributed at all scales (Fig. 3). In plot 2 the spatial distribution of NR resulted significantly clumped at all the distances for all the species, except for the saplings of Picea abies exhibiting a random distribution at $1 \mathrm{~m}$ (Fig. 3). On the contrary, in plot 3 the spatial pattern of all the individuals of NR was random at all scales for all species, except for Fagus sylvatica that showed a clumped distribution at all the distances excluding 4 and $8 \mathrm{~m}$ (Fig. 3).

\subsection{Bivariate point pattern analysis}

Bivariate analysis indicated a negative spatial association (repulsion) between Abies alba and Ostrya carpinifolia at all scales in plot 2, and between Abies alba and Castanea sativa and Fagus sylvatica versus Castanea sativa in plot 1 (Fig. 4) at $1 \mathrm{~m}$.

On the contrary, a significant attraction between Abies alba and Fagus sylvatica was found at short scales in plot 1 and 3 (Fig. 4). Similarly, in plot 2, bivariate analysis indicated a significant attraction between Abies alba and Picea abies at one meter and between Ostrya carpinifolia and Picea abies at all scales (Fig. 4).

The interactions between adult trees and NR saplings were different in the three plots. An independent behaviour and a significant repulsion at all scales were found in plot 3 and 1 , respectively (Fig. 4). On the contrary, in plot 2 the spatial pattern of adult trees and NR resulted independent up to $5 \mathrm{~m}$, and positively associated for greater distances (Fig. 4).

\subsection{Age-structure and spatial-temporal dynamic}

Only the data of Castanea sativa, Abies alba and Picea abies are considered in this section, since the age of Fagus sylvatica and Ostrya carpinifolia were not collected. In all the plots, agestructure of saplings showed a bell-shaped curve, indicating that the establishment process of the NR was not continuous but temporally limited (Fig. 5).

In plot 1 a relative peak of Abies alba saplings occurred in the two years immediately after the thinning carried out in 1986 (Fig. 5).

The process of NR started earlier in plot 1 than in plots 2 and 3 (Fig. 5). However, the age-structures of the three plots were roughly overlapping and in particular the peak of NR occurred for all the plots between 20 and 24 years before the collection of the data (2002).

Only for plot 1 the correlograms in Figure 6 showed a positive and significant autocorrelation for the age of all the individuals of NR. For Abies alba saplings, also diameter and height other than age showed a positive autocorrelation in plot 1 . Because of the limited number of the Castanea sativa and Fagus silvatica saplings, it was impossible to calculate correctly the Moran I for these species. In plots 2 and 3, whatever the parameter considered (age, diameter, height), no autocorrelation was found, except for the height of Abies alba in plot 3. Also in these plots the scarce number of individuals did not allow to calculate the Moran I for the least-frequent species.

\section{DISCUSSION}

The prevalence of Abies alba in the species composition of NR appears related to the abundance of Abies alba seed-trees 


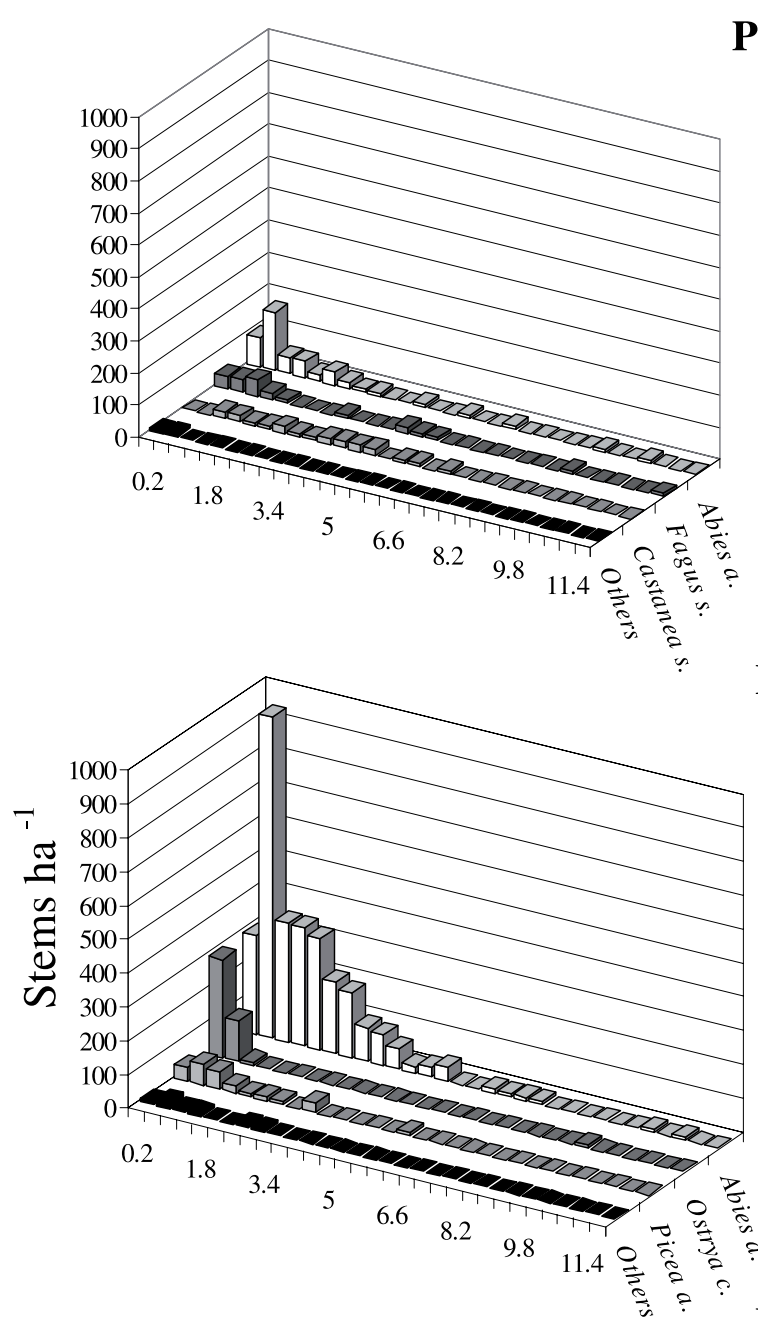

Plot 1

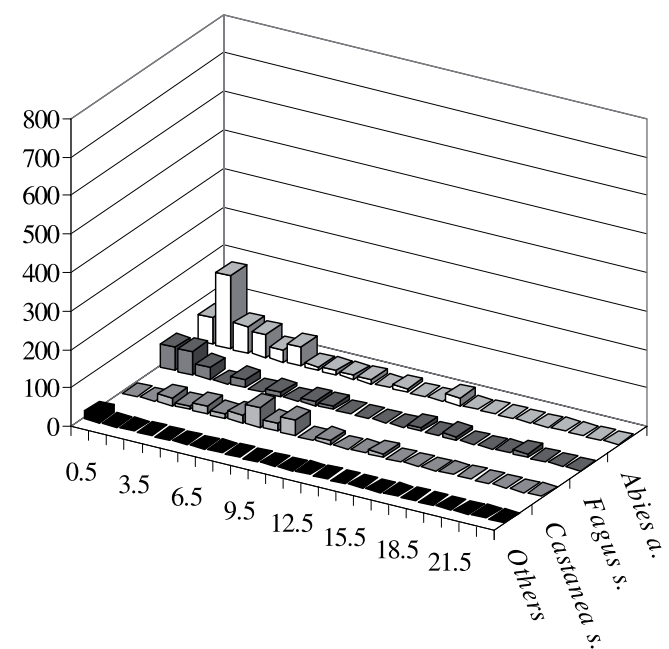

Plot 2

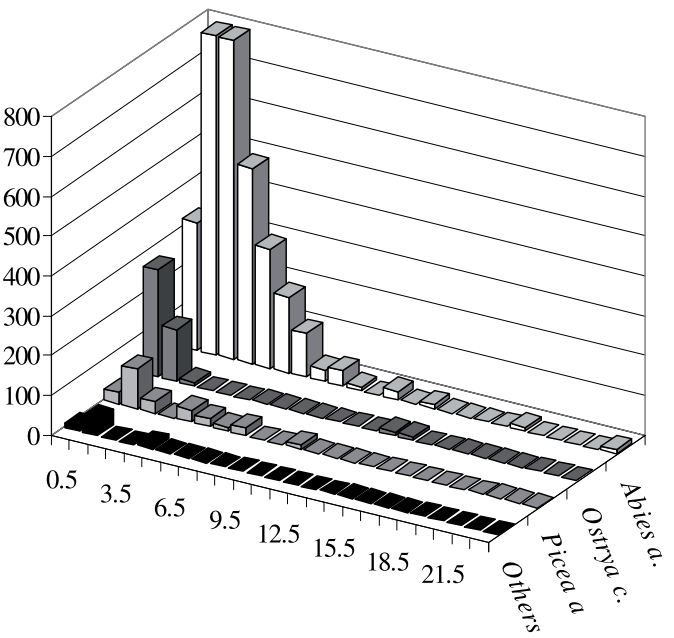

Plot 3

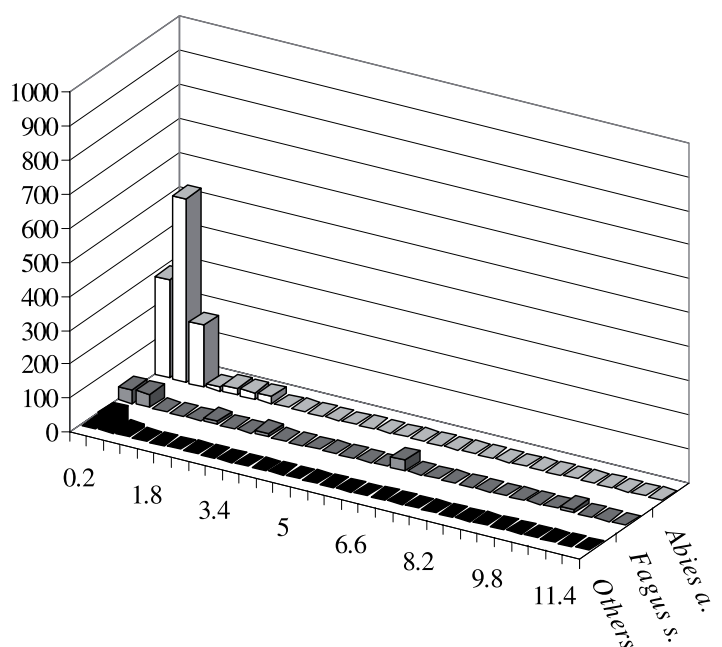

Height classes (m)

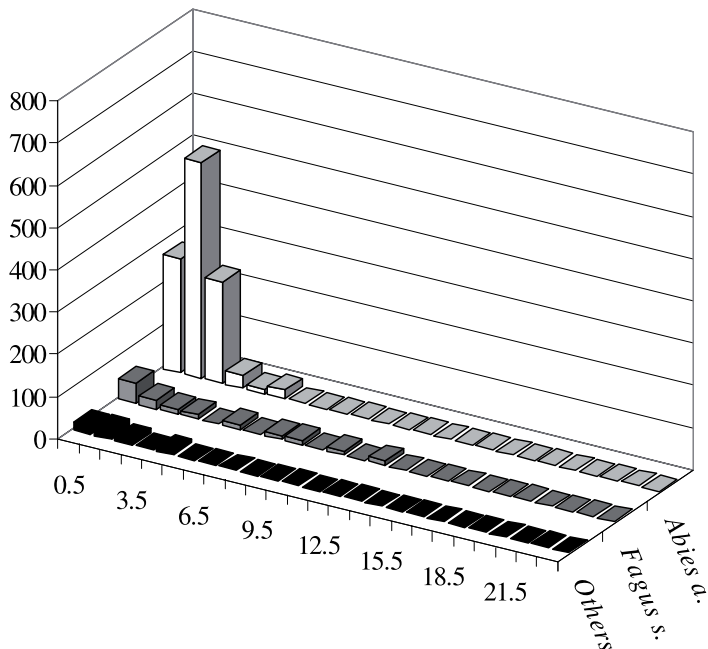

Diameter classes $(\mathbf{c m})$

Figure 1. Diameter and height distribution of natural regeneration in the three plots. 

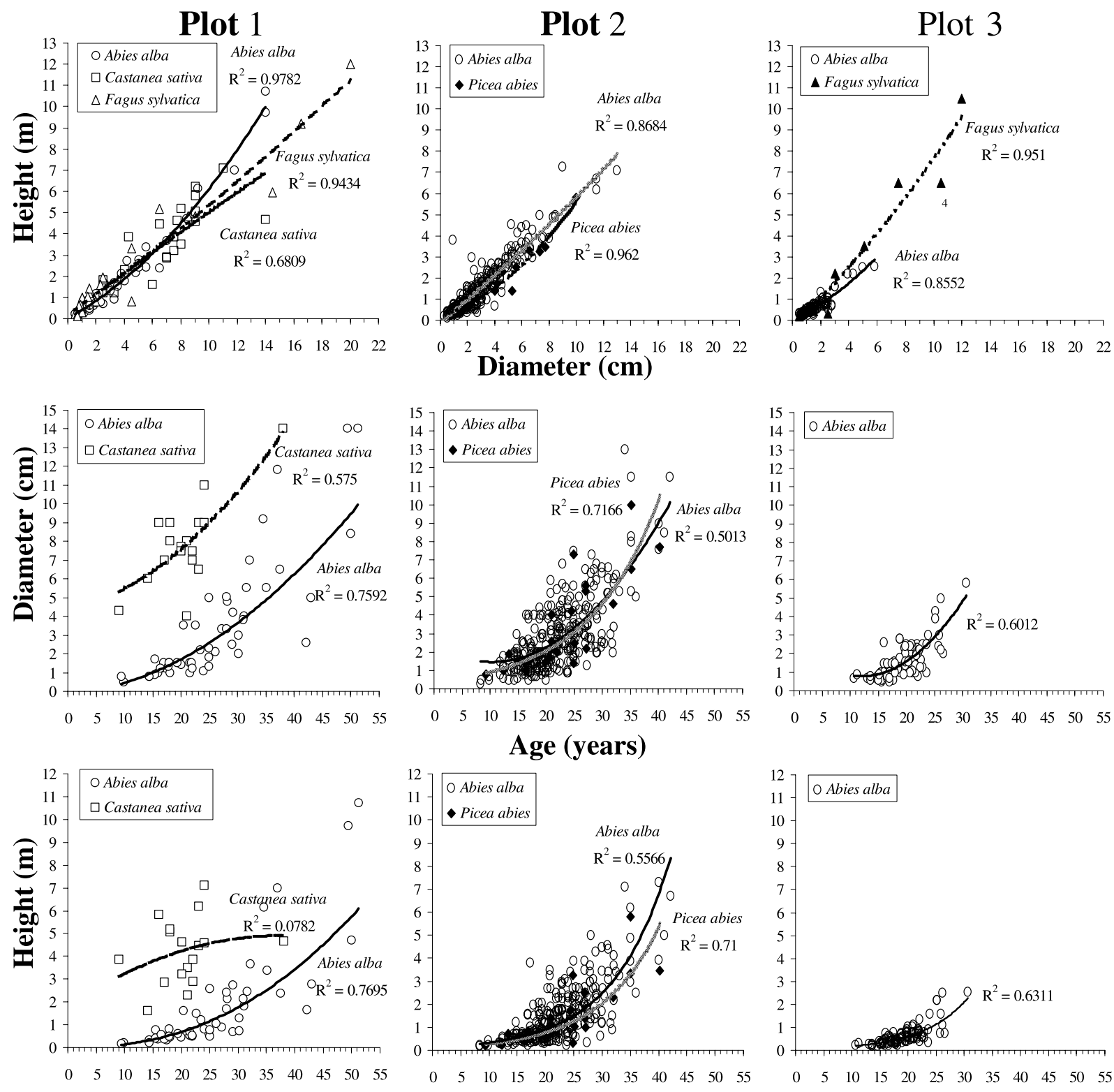

Age (years)

Figure 2. Height-diameter, diameter-age and height-age relationships for the saplings of the species mapped in the three plots.

in the study area and to the strong competition capacity of Abies alba in these environmental conditions. The efficient seed dispersion and the high capacity to withstand low light levels for long periods account for the supremacy of this species in the understorey environment of Pinus nigra stands [12, 23, 45]. The presence of Castanea sativa and Picea abies saplings in the understorey of plot 1 and 2 is also associated with the presence of seed-trees in the neighbourhood. Furthermore, for Castanea sativa animals could have significantly contributed to the seed dispersion [3]. However, for this light demanding and fast growing species [41] the absence of a significant correlation between age and height of saplings indicates a strong inhibition of the vertical growth and suggests a secondary role of this species in the ecological succession of pine stands in this area.

Natural regeneration of Pinus nigra was not observed in our plots. The weak competitive capacity of pioneer species in these environmental conditions indicates that the Pinus nigra plantation significantly changed the microclimate and the soil environment, making it suitable for more demanding species.

The tendency of NR to follow clumped distribution (only in the plot 3 this tendency was not statistically significant) suggests that the suitable conditions for seed germination and seedlings 
Plot 1
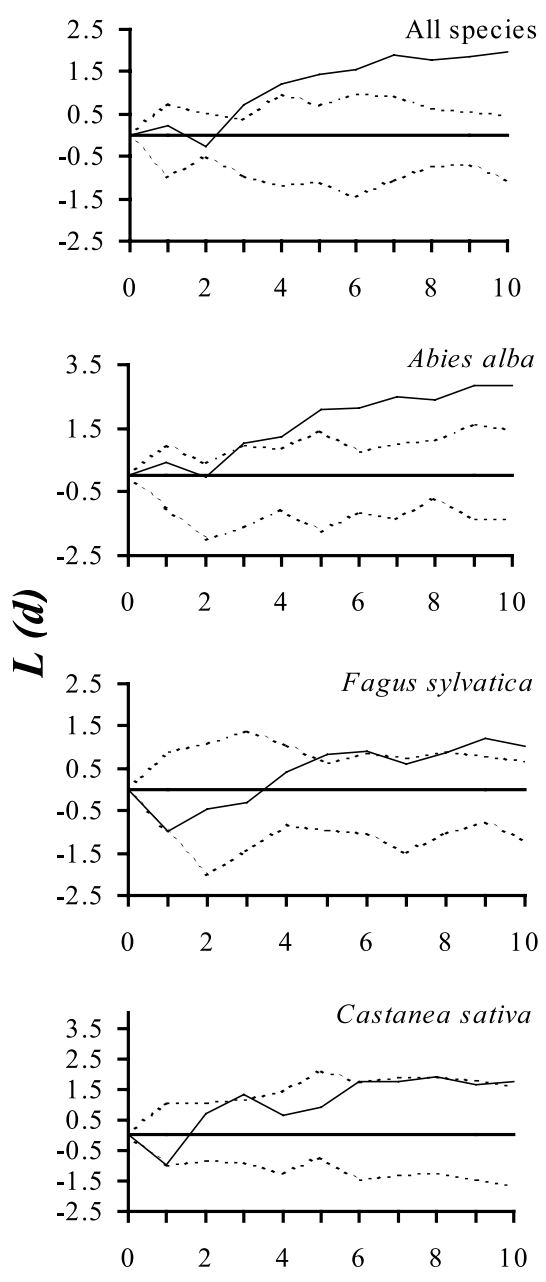

Plot 2
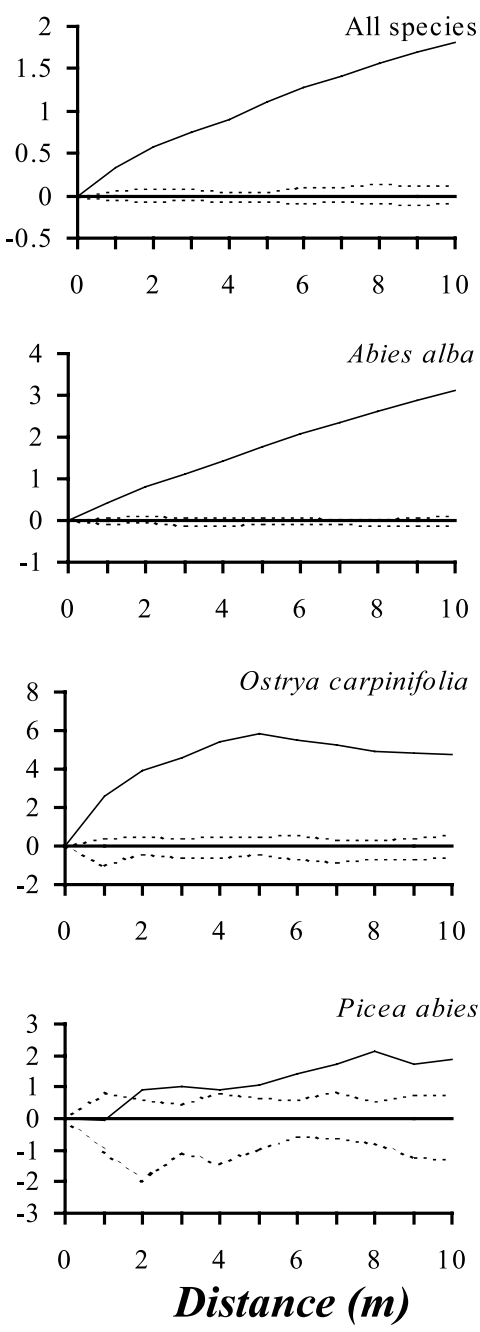

Plot 3
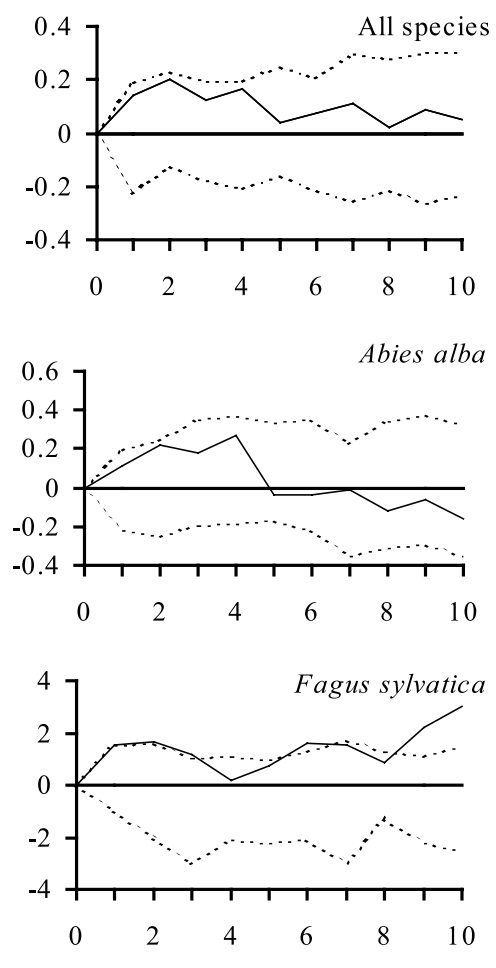

Figure 3. Ripley's $K$ for all individuals and for the single species forming natural regeneration in the three plots. The square root transformation, $L(d)$, of the Ripley's $K$ (solid line) has been plotted. The dotted lines give a 95\% confidence envelope for complete spatial randomness according to the Monte Carlo simulation method.

establishment were concentrated in micro-areas variously distributed within the stand. The origin of the clumped pattern can be ascribed to several factors. In a study on the spatial interactions between Acer saccharum and Tsuga canadensis, Felich et al. [20] proposed three main factors which influence forests patterns: (1) disturbance history; (2) competitive interactions; (3) invaders. These three factors can predispose a stand to follow or not a non-random spatial structure. The published literature on this matter showed a predominance of random patterns in unmanaged forests $[47,50]$. Clustering patterns are quite rare and can be observed in managed forests [13, 24]. However, the density of the stand and the scale used to quantify the pattern can significantly affect the final result [14]. The spatial distribution of trees can show one pattern at certain scales and another one at other scales. Moeur [34] reported that trees in hemlock forests tend to show regular pattern at smaller scales and clustered pattern at larger scales. The presence of scarcely modifiable environmental factors and/or the occurrence of disturbances on small areas scattered by a non-random pattern can be the reason of the clumped distribution of NR. In particular, the non-random distribution of tree mortality and the complexity of microsites are reported as main causes of clumped pattern by Kenkel [28] and Moeur [34]. Our data did not enable us to identify precisely the ecological factors causing the prevalence of the clumped over the random pattern. Nevertheless, the autocorrelation analysis, applied to the age and to the bio-metric parameters (diameter and height), providing useful information on the chronological and morphological differentiation within the aggregation nuclei can help us to infer on the nature of the causal factors. In plot 1 the positive autocorrelation for the age of saplings indicates that the clumped pattern is the result of aggregation nuclei in which the saplings have a similar age. 
Plot 1
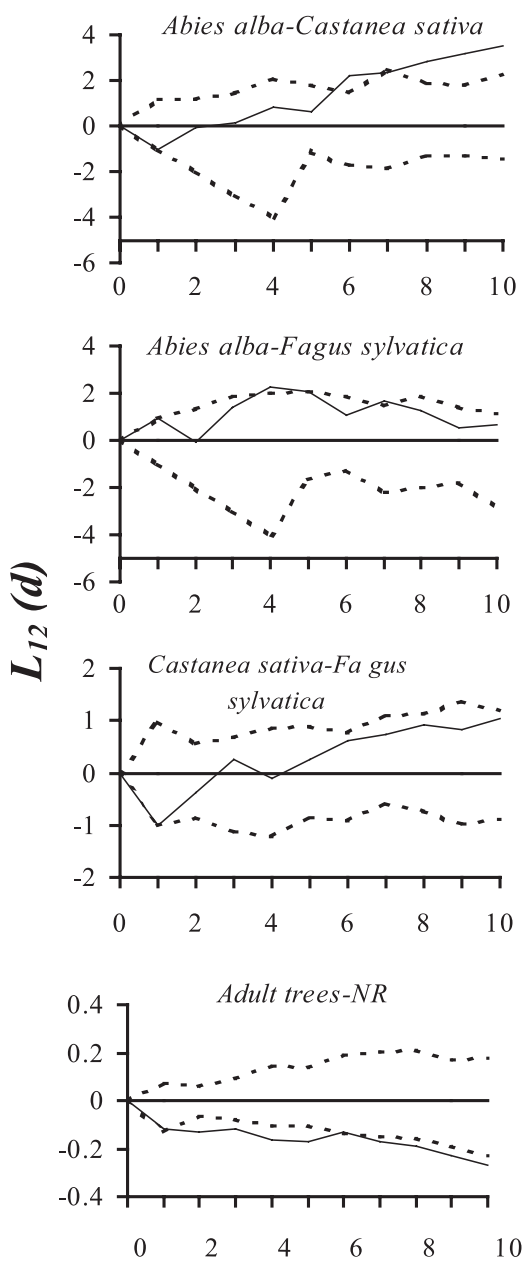

Plot 2
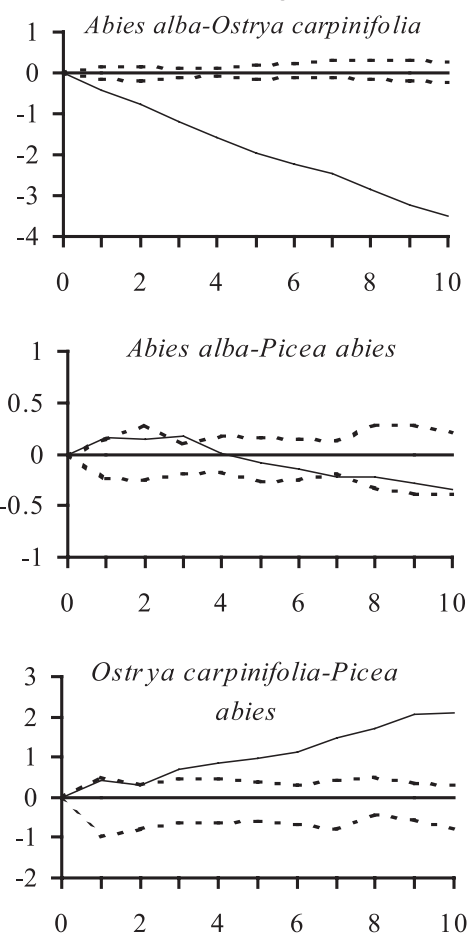

Adult trees-NR

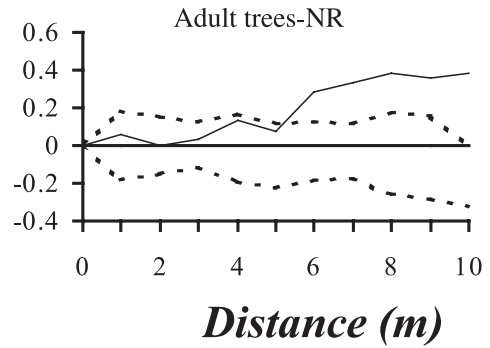

Plot 3
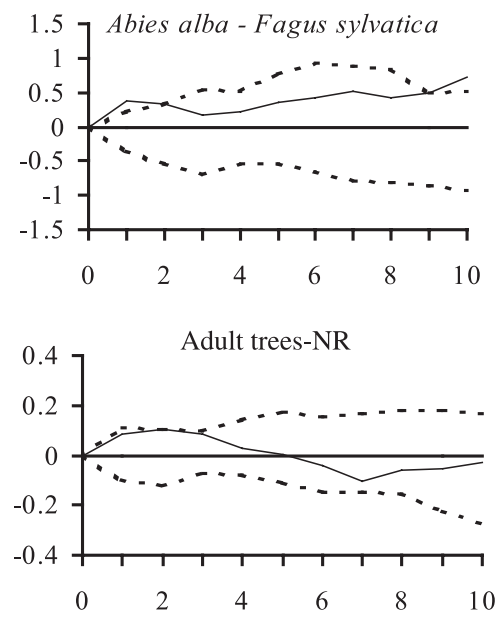

Figure 4. Bivariate Ripley's $K$ between spatial distribution of different species showing significant (95\%) attractive (above the confidence envelope) or repulsion (bellow the confidence envelope) responses. The square root transformation, $L(d)$, of the Ripley's $K$ (solid line) has been plotted. The dotted lines give a $95 \%$ confidence envelope for complete independence of two spatial patterns according to the Monte Carlo simulation method.

Considering the amplitude of the age-structure (from 8 to 52 years) of NR in plot 1, these small even-aged patches must be uneven-aged among them. This means that each micro-area was suitable for NR establishment for few years. The positive autocorrelation for the age, calculated considering all the species together, was not found for diameter and height of saplings. This discrepancy could arise from the different growth rates of Abies alba and Castanea sativa and from the intra-specific competition that causes a social differentiation between plants of similar age. This observation agrees with the asymmetric distribution of diameters and heights of saplings, observed in plot 1 , and suggests, according to Weiner's theories [7, 52], that saplings experienced more competition for light than for other resources. When competition is asymmetric, as in competition for light, higher individual suppress growth of smaller ones more than would be expected from their relative size [54]. The asymmetry in size-distribution as consequence of the competition process was found to increase with age and plant density [53] of population. These factors could explain because the asymmetry in size-distribution was higher in plot 1 and 2 than in plot 3 [53].

The absence of significant autocorrelation for the age in plot 2 and 3 suggests that the colonisation process in these plots occurred in the same micro-areas for a more extended period (several years). This colonisation modality is consistent with an uneven-aged structure within each NR aggregation nucleus. Thus, in our study the clumped pattern of NR was prevailing irrespective of the different environmental conditions that NR experienced in the three plots. However, environmental conditions seem to have affected the age-structure within the aggregation nuclei by influencing the duration of the suitable conditions for NR establishment in the micro-sites. As confirmed by 

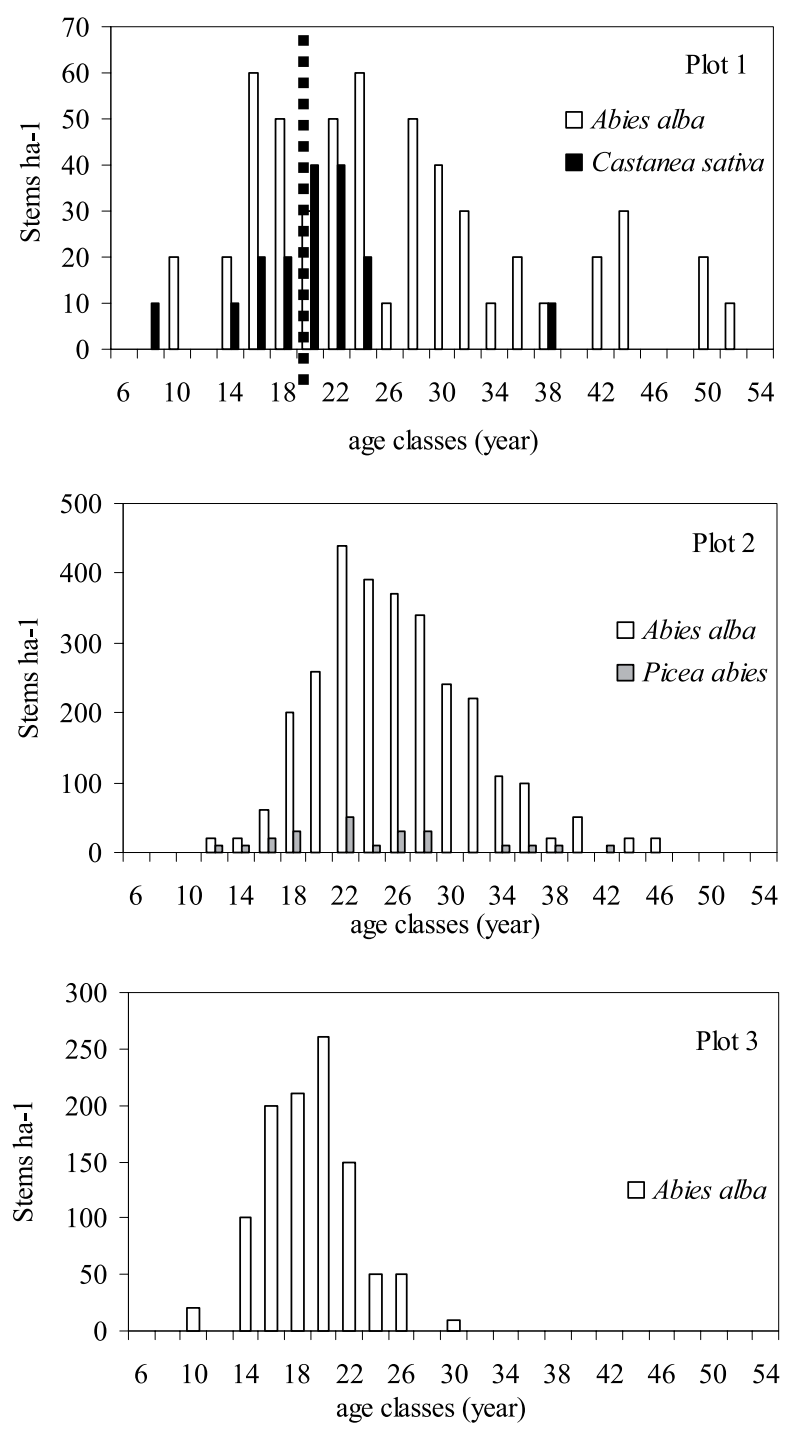

Figure 5. Age-structures of all saplings mapped in the three plots. Broken line indicates the thinning.

autocorrelation analysis for age, in plots 2 and 3 the period of suitable conditions for the establishment of NR lasted several years in the same micro-areas; on the contrary, in plot 1 it lasted a few years and occurred in a few micro-areas per time.

These distinct colonisation dynamics suggest that the duration of the disturbances or the nature of the factors provoking the establishment of NR should be different. In particular, for plots 2 and 3 un-modifiable factors, such as micro morphology [6], soil characteristics or long-term disturbance with effect on soil or canopy structure (large gaps) could have caused the observed clumped distribution of NR formed by several uneven-aged groups of saplings [18]. On the contrary, in the plot 1 short-term disturbances, such as tree mortality with sudden and temporary canopy openings or litter removal could explain the observed clumped pattern made up by several even-aged groups of saplings [18].
The ecological requirements of the species, especially with respect to light, explain the results obtained with bivariate point pattern analysis for NR species. For instance, in plots 1 and 3 Abies alba and Fagus sylvatica, two shade-tolerant species [12, 29, 39, 40, 48, 49], showed a significant spatial attraction at small scales, while they are independent at greater scales. In the same way, Abies alba versus Picea abies at small scales, and the latter species versus Ostrya carpinifolia-a light demanding tree species - exhibited a significant attraction, confirming the ecological plasticity of Picea abies, whose seedling can exploit efficiently different light conditions [23]. On the contrary, a significant spatial repulsion was observed between species with different light requirements; this is the case of Abies alba versus Ostrya carpinifolia in plot 2 or Castanea sativa versus Abies alba and Fagus sylvatica at small scales in plot 1.

The significant repulsion between adult trees and NR in the plot with the highest value of basal area (Plot 1), suggests that light environment is an important factor in regulating NR process in these stands. This is confirmed also by the positive effect of thinning observed in the same plot. On the contrary, the attraction between young and adult trees observed at small scales in plot 3, could be related to a positive effect of adult trees on the microenvironment in terms of wind protection, soil condition (moisture, nutrients, temperature ) and absence of herbaceous species [27]. This "nurse effect" has been found by other authors in severe environmental conditions and often relate to the reduction in wind and snowpack close to adult trees [11]. The fact that plot 3 is north-west oriented, and located in a very windy area, could account for the observed attraction between mature pine trees and NR saplings.

Whatever the species and the plot, the colonisation process in the present study was temporally limited. The overlapping of the age-structures of NR in the three plots irrespective of the species suggests the involvement of environmental factors acting at a regional scale. For instance, the irregularity of climate conditions, especially the annual rainfall variations were reported by Oliver and Larson [38] as the main factor triggering the NR process. However, many other factors such as the irregularity of seed production, the annual changes in seed eaters population and pathogens diffusion could account for the interannual variation in NR [18].

In conclusion, the combined use of point pattern and surface spatial analysis associated with size- and age-structure data of NR resulted an efficient tool to describe accurately the NR process within Pinus nigra stands in order to infer on the nature of the causal factors.

Within Pinus nigra stands with similar age but different growth rates, various dynamics of space colonisation by NR were observed. Whatever the plot these dynamics produced a clumped distribution of NR, whose origin can be alternatively related to scarcely modifiable factors (soil characteristics, micro-morphology, etc.), to disturbances with long-term effect (large gaps) or to short term disturbances (small gaps, temporary canopy opening, moderate thinning) [18].

Finally, although predicting the evolution of the examined stands in relation to the present colonisation strategies is difficult, an increase of structural complexity and species diversity is likely. 


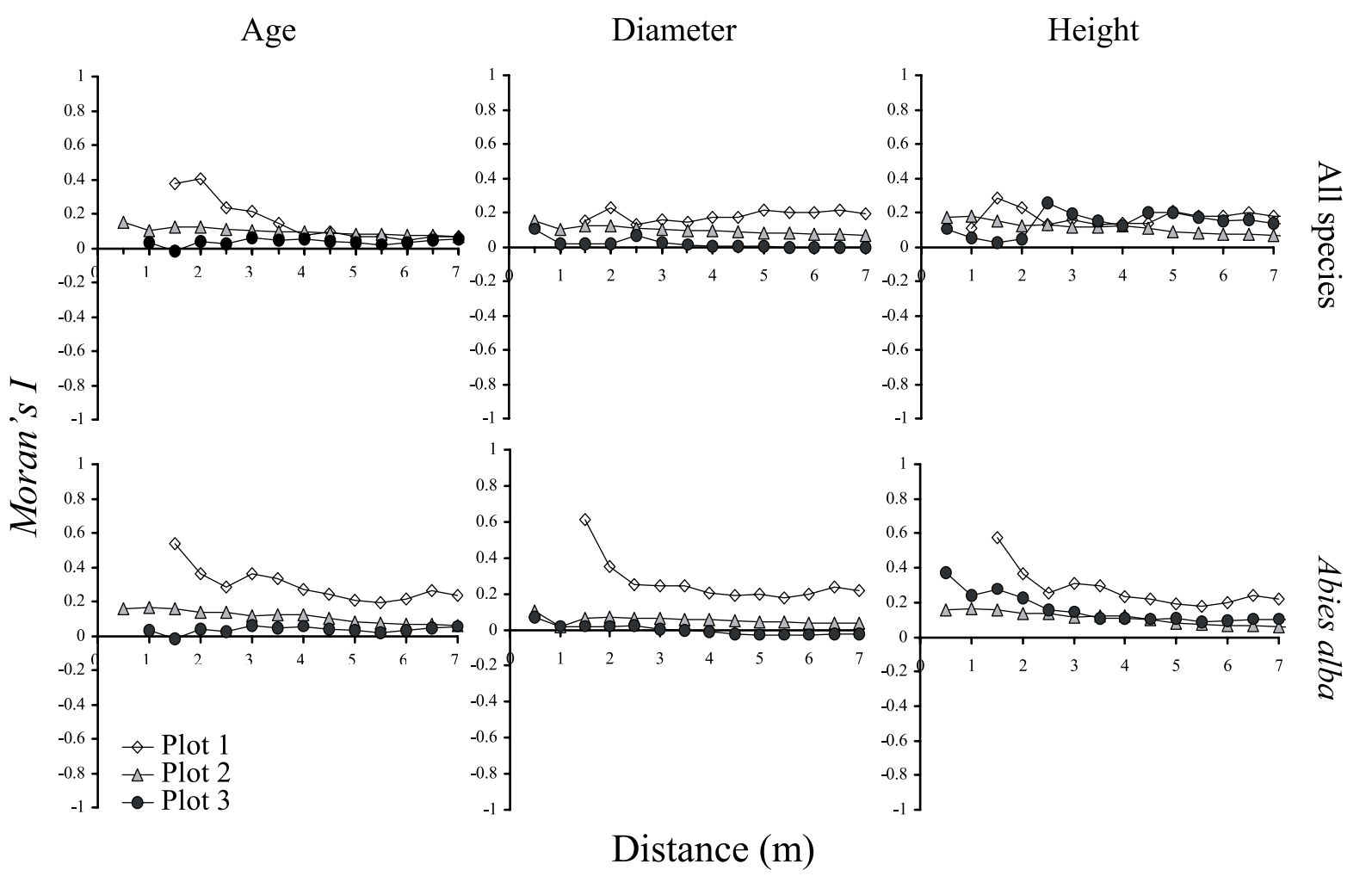

Figure 6. Spatial correlograms (Moran's $I$ ) for age, height and basal diameter of all natural regeneration and Abies alba saplings mapped in the three plots.

Acknowledgements: This paper is dedicated to the late Prof. Umberto Bagnaresi (1927-2003), who learned us the love for forest and for ecological research. We thank Stefano Cinti, Stefania Coslovi and Virginia Lopez Usieto for their help in field work. We also thank the reviewers for their constructive comments that greatly improved the manuscript. The work was supported by MiPAF (Ministero delle Politiche Agricole e Forestali of Italy) within the RISELVITALIA national project.

\section{REFERENCES}

[1] Amorini E., Fabbio G., La gestione dei rimboschimenti di pino nero, Monti e Boschi 4 (1992) 27-30.

[2] Awada T., Henebry G.M., Redmann R.E., Sulistiyowati H., Picea glauca dynamics and spatial pattern of seedlings regeneration along a chronosequence in the mixedwood section of the boreal forest, Ann. For. Sci. 61 (2004) 789-794.

[3] Bacilieri R., Bouchet M.A., Bran D., Grandjanny M., Maistre M., Perret P., Romane F., Natural germination as resilience component in Mediterranean coppice stands of Castanea-sativa Mill. and Quercus-ilex L., Acta Oecol. 15 (1994) 417-429.

[4] Bailey T.C., Gatrell A.C., Interactive spatial data analysis, Longman Scientific and Technical Unlimited, Essex, 1995.

[5] Barot S., Gignoux J., Menaut J.C., Demography of a savanna palm tree: predictions from comprehensive spatial pattern analyses, Ecology 80 (1999) 1987-2005.

[6] Beatty S.W., Influence of microtopography and canopy species on spatial patterns of forest understory plants, Ecology 65 (1984) $1406-1419$.
[7] Beland M., Lussier J..M., Bergeron Y., Longrpre M.H., Beland M., Structure, spatial distribution and competition in mixed jack pine (Pinus banksiana) stands on clay soils of eastern Canada, Ann. For. Sci. 60 (2003) 609-617.

[8] Bernetti G., Le pinete di pino nero, I quaderni di Monti e Boschi $\mathrm{n}^{\circ} 4$, I boschi della Toscana, Edagricole, Bologna, 1987, pp. 145-157.

[9] Bernetti G., I pini neri: pino nero d'Austria, pino nero di Villetta Barrea e pino laricio di Calabria, in: Selvicoltura speciale, UTET, Torino, 1995, pp. 132-142.

[10] Bianchi L., Paci M., Tipologia delle pinete di pino nero del Parco Nazionale Foreste Casentinesi, Monte Falterona e Campigna, Ann. Acc. It. Sc. For. LI (2002) 73-120.

[11] Camarero J.J., Gutiérrez E., Fortin M.J., Spatial pattern of subalpine forest-alpine grassland ecotones in the Spanish Central Pyrenees, For. Ecol. Manage. 134 (2000) 1-16.

[12] Chen H.Y.H., Kayahara G.J., Klinka K., Effects of light and substrate on planted conifer seedlings in coastal British Columbia, Northwest Sci. 78 (2004) 101-110.

[13] Chen J., Bradshaw G.A., Forest structure in space: a case of study of an old growth spruce-fir forest in Changbaishan Natural Reserve, PR China, For. Ecol. Manage. 120 (1999) 219-233.

[14] Cressie N.A., Statistics for spatial data, John Wiley and Sons, New York, 1993.

[15] Dale M.R.T., Spatial pattern analysis in plant ecology, Cambridge University Press, Cambridge, 1999.

[16] Diggle P.J., Statistical analysis of point patterns, Academic Press, London, 1983.

[17] Duncan R.P., Competition and the coexistence of species in a mixed podocarp stand, J. Ecol. 79 (1991) 1073-1084. 
[18] Fajvan M.A., Seymour R., Canopy stratification, age structure, and development of multicohort stands of eastern white pine, eastern hemlock, and red spruce, Can. J. For. Res. 23 (1993) 1799-1809.

[19] Fortin M.-J., Dale M.R.T., ver Hoef J., Spatial analysis in ecology, in: El-Shaarawi A.H., Piegorsch W.W. (Eds.), Encyclopedia of Environmetrics, John Wiley and Sons Ltd, Chichester, 2002, pp. 2051-2058.

[20] Frelich L.E., Calcote R.L., Davis M.B., Pastor J., Patch formation and maintenance in an old-growth hemlock-hardwood forest, Ecology 72 (1993) 513-527.

[21] Gambi G., Il pino nero, pianta della bonifica montana, Ann. Ist. Sperim. Selv. 14 (1983) 3-45.

[22] Gracia M., Retana J., Roig P., Mid-term successional patterns after fire of mixed pine-oak forests in NE Spain, Acta Oecol. 23 (2002) 405-411.

[23] Grassi G., Bagnaresi U., Foliar morphological and physiological plasticity in Picea abies and Abies alba saplings along a natural light gradient, Tree Physiol. 21 (2001) 959-967.

[24] Grassi G., Minotta G., Tonon G., Bagnaresi U., Dynamics of Norway spruce and silver fir natural regeneration in a mixed stand under uneven-aged management, Can. J. For. Res. 34 (2004) 141149.

[25] Geary R.C., The contiguity ratio and statistical mapping, Incorporated Statistician 5 (1954) 115-145.

[26] Haase P., Spatial pattern-analysis in ecology based on Ripley Kfunction - introduction and methods of edge correction, J. Veg. Sci. 4 (1995) 575-582.

[27] Holtmeier F.K., Broll G., The influence of tree islands and microtopography on pedoecological conditions in the forest Alpine tundra ecotone on Niwot Ridge, Colorado Front Range, USA, Arctic Alpine Res. 24 (1992) 216-228.

[28] Kenkel N.C., Pattern of self-thinning in Jack pine: testing the random mortality hypothesis, Ecology 69 (1988) 1017-1024.

[29] Kuppers M., Schneider H., Leaf Gas-Exchange of beech (Fagus sylvatica L.) Seedlings in Lightflecks - Effects of fleck length and leaf temperature in leaves grown in deep and partial shade, TreesStruct. Funct. 7 (1993) 160-168.

[30] Kuuluvainen T., Rouvinen S., Post-fire understorey regeneration in Boreal Pinus sylvestris forest sites with different fire histories, J. Veg. Sci. 11 (2000) 801-812.

[31] Legendre P., Fortin M.J., Spatial pattern and ecological analysis, Vegetatio 80 (1989) 107-138.

[32] Lotwick H.W., Silverman B.W., Methods for analysing spatial processes of several types of point, J. Roy. Stat. Soc. B 44 (1982) 406413.

[33] Meoni G., Tavola cormometrica ad una sola entrata del pino nero per il comune di Granaglione, in: Castellani C. (Ed.), Tavole stereometriche ed alsometriche costruite per i Boschi Italiani, ISAFA, Trento, 1982, p. 190.

[34] Moeur M., Characterizing spatial patterns of trees using stem-mapped data, For. Sci. 39 (1993) 756-775.

[35] Moran P.A.P., Notes a continuous stochastic phenomena, Biometrika 37 (1950) 17-23

[36] Ordonez J.L., Franco S., Retana J., Limitation of the recruitment of Pinus nigra in a gradient of post-fire environmental conditions, Ecoscience 11 (2004) 296-304.
[37] Ordonez J.L., Retana J., Espelta J.M., Effects of tree size, crown damage, and tree location on post- fire survival and cone production of Pinus nigra trees, For. Ecol. Manage. 206 (2005) 109-117

[38] Oliver C.D., Larson B.C., Forest stand dynamics, McGraw-Hill, New York, 1990

[39] Paluch J.G., The influence of the spatial pattern of trees on forest floor vegetation and silver fir (Abies alba Mill.) regeneration in uneven-aged forests, For. Ecol. Manage. 205 (2005) 283-298.

[40] Ponge J.F., Ferdy J.B., Growth of Fagus sylvatica saplings in an old-growth forest as affected by soil and light conditions, J. Veg. Sci. 8 (1997) 789-796

[41] Proietti P., Palliotti A., Famiani F., Antognozzi E., Ferranti F., Andreutti R., Frenguelli G., Influence of leaf position, fruit and light availability on photosynthesis of two chestnut genotypes, Sci. Hortic. 85 (2000) 63-73.

[42] Ripley B.D., Modelling spatial patterns (with discussion), J. R. Stat. Soc. Bull. 39 (1977) 172-212.

[43] Ripley B.D., Tests of "randomness" for spatial points patterns, J. R. Stat. Soc. Bull. 41 (1979) 368-374.

[44] Ripley B.D., Spatial statistics, Wiley, New York, 1981.

[45] Robakowski P., Wyka T., Samardakiewicz S., Kierzkowski D., Growth, photosynthesis, and needle structure of silver fir (Abies alba Mill.) seedlings under different canopies, For. Ecol. Manage. 201 (2004) 211-227.

[46] Sawada M., Rookcase: an Excel 97/200 visual basic add-in exploring global and local spatial autocorrelation, Bull. Ecol. Soc. Amer. 80 (1999) 231-234.

[47] Szwagrzyk J., Small-scale spatial patterns of trees in a mixed Pinus sylvestris-Fagus sylvatica forest, For. Ecol. Manage. 51 (1990) 301-315.

[48] Schutz J.P., Opportunistic methods of controlling vegetation, inspired by natural plant succession dynamics with special reference to natural outmixing tendencies in a gap regeneration, Ann. For. Sci. 61 (2004) 149-156.

[49] Thibaut B., Comps B., Rucart M., Soroste S., Okwo C.N., Growth of young beeches (Fagus-Sylvatica L.) in an even-aged, 18-year old natural beech regeneration, Ann. Sci. For. 49 (1992) 111-131.

[50] Tomppo E., Models and methods for analyzing spatial patterns of trees, Comm. Instit. For. Fenn No. 138, The Finnish forest research institute, Helsinki, 1986.

[51] Vallauri D.R., Aroson J., Barbero M., An analysis of forest restoration 120 years after reforestation on badlands in the southwestern Alps, Restor. Ecol. 10 (2002) 16-26.

[52] Weiner J., Asymmetric competition in plant populations, Trends Ecol. Evol. 5 (1990) 360-364.

[53] Xue L., Hagihara A., Density effect, self-thinning and size distribution in Pinus densiflora Sieb. et Zucc. stands, Ecol. Res. 14 (1999) $49-58$.

[54] Yastrebov A.B., Different types of heterogeneity and plant competition in monospecific stands, Oikos 75 (1996) 89-97.

[55] Zerbe S., Restoration of natural broad-leaved woodland in Central Europe on sites with coniferous forest plantations, For. Ecol. Manage. 167 (2002) 27-42. 